\title{
Social class differences in health and care in the year before death
}

\author{
Ann Cartwright
}

\begin{abstract}
Study objective-The aim was to identify any social class differences in health and care in the year before death emerging from a wider study of life before death.

Design and setting-Data were collected at interviews, mainly of close relatives, with those who knew most about the people's lives in the year before they died. The sample was a random sample of adult (15 and over) deaths in 10 areas of England in 1987.
\end{abstract}

Subjects-Information was obtained about 639 persons, $80 \%$ of the initial sample of 800 deaths.

Main results-While middle class people die at an older age, the symptoms and physical restrictions reported for middle class and working class people were similar, and middle class people were reported to have a better quality of life before death. More working class people were felt to be in financial need.

Conclusions-Money and class contribute to the quality of life before death as well as postponing death.

Social class differences in mortality persist ${ }^{1-3}$ and it appears that most of the differentials must be attributed to socioeconomic environment, lifestyles, and circumstances before death rather than to changing social class as a result of ill health. ${ }^{4}$ If poverty and deprivation are the main causes of premature death and lesser life expectancy in the lower social classes, ${ }^{5}$ what impact do these have on the quality and circumstances of life before death? To what extent do people in different social classes have different health problems, receive different sorts of care and experience different types of deprivation in the year before they die?

A study of the last year of the lives of a random sample of adults dying in $1969^{6}$ found no social class differences in reported symptoms or restrictions or the type of help people needed except that working class people more often needed financial help. There were also clear variations in housing conditions and household equipment with social class. A comparable survey of deaths in $1987^{7}$ makes it possible to look again at the nature and extent of class differences in a range of circumstances at this stage of life, and see whether the same pattern of similarity and variation still persists.

\section{Methods}

The study was based on a random sample of adult (aged 15 years or over) deaths registered in 10 areas of England in October and November 1987. Interviewers tried to contact the person who could tell them the most about the last 12 months in the lives of these people, and information was obtained about $639,80 \%$ of the initial sample of 800 deaths. In just over a third, a husband or wife was interviewed, a son or daughter in a quarter, other relatives in a sixth, friends and neighbours in a tenth, and an official, mostly staff in residential homes, in a tenth.

Informants were asked about the health problems and restrictions that the deceased had experienced in the year before death and about the help and care that he or she had been given by hospitals, ${ }^{8}$ other residential institutions, ${ }^{9}$ general practitioners, ${ }^{10}$ community nurses, ${ }^{11}$ and by family and friends. ${ }^{12}$ They were also asked about their perceptions of any unmet needs for care, about the adequacy and nature of communication with the professionals involved and about the deceased's social circumstances. For further details about the study see Cartwright and Seale. ${ }^{7}$ Data about occupation, or for married and widowed women about their husband's occupation, were taken from the death registration forms and then classified by social class using the Classification of Occupations $1980 .{ }^{13}$ Eight per cent of the deaths could not be classified in this way-three quarters of these were deaths of women. For analysis, professional, intermediate, and skilled non-manual occupations have been taken as middle class, and manual skilled, partly skilled, and unskilled occupations as working class. Among those that could be classified, $31 \%$ of the male deaths were middle class, and a similar proportion ( $34 \%$ ) of the female deaths.

\section{Results}

NATIONAL STATISTICS

National statistics show clear social class trends in the standardized mortality ratios and in the years of potential life lost. ${ }^{3}$ The table shows that in the 1987 sample of deaths a higher proportion of the middle class ones occurred at ages 75 years or more: $60 \%$ compared with $50 \%$ of working class deaths; and more working class deaths occurred under 65 years: $25 \% v 17 \%$. (Tests of differences in proportions have been applied to the data constantly and have influenced decisions about what differences to present and how much verbal "weight" to attach to them. Attention is only drawn to differences which are unlikely to have occurred by chance five or more times in 100 unless specifically stated.)

The sample was too small to show class differences in cause of death, but for cancer there 
was a difference in the expected direction that did not reached statistical significance: $23 \%$ of the middle class deaths compared with $30 \%$ of the working class ones were attributed to cancer. (The classification of death was done by the Office of Population Censuses and Surveys and taken from the death registration form.)

\section{FAMILY AND SOCIAL CIRCUMSTANCES}

Given their older age at death it might be thought that fewer of the middle class people would have a husband or wife who survived them although most of their spouses too would have a longer life expectancy. In practice there were no significant class differences in marital status but the proportions with surviving spouses at the time of death were $43 \%$ of the middle class and $49 \%$ of the working class-a difference which did not reach statistical significance. More of the working class had brothers or sisters who were alive- $69 \%$ compared with $57 \%$-but there was no difference between the two groups in the proportion with living children $(71 \%$ overall), and the proportion living alone during the last year of their lives was similar $-32 \%$ altogether (those who had lived in an institution for a year or more before their death have been excluded from this last figure as the question was not asked about them).

PLACE OF DEATH

A comparatively high proportion of middle class deaths took place in old people's homes or nursing homes: $17 \%$ compared with $10 \%$ of working class deaths. The difference between the two groups remained if the comparison is restricted to deaths of people aged 85 years or more, for which the proportions were $47 \%$ and $25 \%$. In relation to this, staff of residential homes were more often interviewed about the deaths of middle class people than of working class people: $13 \% v 6 \%$ There were no other class differences in place of death.

\section{ADMISSION TO RESIDENTIAL HOMES}

Similar proportions of middle class and working class people who died, $8 \%$, had spent at least some of the last year of their life in residential homes

Social class differences in health, care and circumstances in the year before death

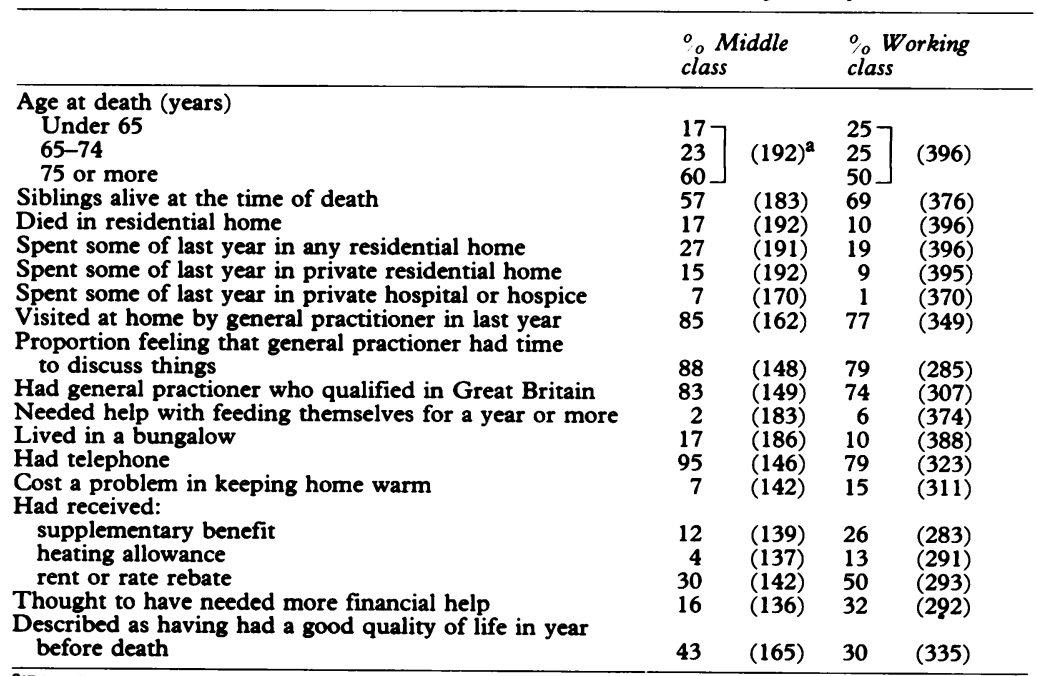

a The figures in brackets are the numbers on which the percentages are based $\left(=100^{\circ}\right)$. Certain exclusions have been made in some instances (see text); in addition small numbers for which information was not available have also been excluded that were run by local authorities, but more middle class people had spent some of this time in private residential homes- $15 \%$ compared with $9 \%$ - and the proportions spending time in any residential home (including those run by charities and other organisations) was $27 \%$ of the middle class, and $19 \%$ of the working class. None of the questions asked about amenities and conditions in the residential homes revealed any significant class difference, although $70 \%$ of middle clas residents compared with $53 \%$ of working class ones had had a room of their own-a difference which did not quite reach statistical significance.

\section{HOME NURSING CARE}

Other analyses from this study have shown that people in residential homes received similar amounts of care from domiciliary nurses as others ${ }^{9}$ but, as in the earlier (1969) study, ${ }^{6}$ older people and those dying from cancer were more likely to have received help at home from a nurse. ${ }^{11}$ As the middle class people who died were older, but rather more of the working class people died of cancer, it might be expected that these tendencies would cancel each other out, and this appeared to be so: the same proportion of middle and working class people, $42 \%$, had had some help from a nurse at home in the 12 months before they died. Among those who had not had any help similar proportions of both social class groups ( $11 \%$ overall) were thought to have needed it. Among those receiving help, rather more of the working class than of the middle class had had this help for six months or more $(43 \% v 29 \%)$ but there was no significant difference in the frequency with which the help was given, or in the type of care received. When asked to describe the help and care the dying people got from nurses as excellent, good, fair, or poor, rather more of the respondents for working class patients opted for fair or poor: $16 \%$ compared with $6 \%$ of respondents for middle class patients.

\section{HOSPITALS AND HOSPICES}

Similar proportions of both middle class and working class people had been admitted to a hospital or hospice during the last year of their lives and they had spent similar lengths of time there, but more of the middle class $(7 \% v 1 \%)$ had been in private hospitals or hospices. In addition more of the middle class people had had a room of their own at some stage of their stay in hospital $(41 \% v 29 \%)$, but if this analysis is confined to stays in NHS hospitals or hospices only, the difference is no longer significant, at $36 \% v 28 \%$. There were no differences between the two groups in the respondents' assessments of the care they had received in hospital. Neither was there any difference in the proportion who had had a domiciliary consultation-a home visit from a doctor based in a hospital or hospice: $14 \%$ overall.

CONTACT WITH GENERAL PRACTITIONERS

The observation that rather more of the middle class than of the working class people who died had been visited at home by a general practitioner in the last year of their lives $(85 \% v 77 \%$ ) can be attributed to the older age of the middle class people; when age was controlled for there was no significant difference. Assessments of the care 
given by general practitioners were also similar for the two groups except that respondents for middle class people were more likely to feel that the general practitioner had had time to discuss things: $88 \% v 79 \%$. Other studies have found that general practitioner consultation times were rather longer with middle class than with working class patients. ${ }^{1415}$

Analyses by various characteristics of the doctors-age, sex, membership of the Royal College of General Practitioners, whether or not the doctor was a registered trainer, average size of list, and country of qualification-revealed one class difference: the middle class people who died were more likely to have had a doctor who qualified in Great Britain: $83 \%$ compared with $74 \%$ of the working class people who died. A similar class difference was observed on a study of general practice covering a wider sample. ${ }^{16}$

\section{SYMPTOMS AND RESTRICTIONS}

It might be expected that because of their greater age at death middle class patients would suffer from more of the symptoms that increased with age. Symptoms which have been shown to do this among those aged 65 or more are constipation, confusion, drowsiness or dry mouth, incontinence, and difficulty seeing and hearing. ${ }^{17}$ None of these, or any of the other 16 specific symptoms asked about, were reported significantly more often for middle class than for working class people. But one of them, a dry mouth, was reported for $37 \%$ of working class people, but for only $28 \%$ of middle class people. It is a symptom which is often a side effect of medicines but there is no evidence that working class people take more medicines than middle class people. ${ }^{18} \mathrm{~A}$ significant difference in one out of 16 symptoms might have occurred just by chance.

There was no indication that middle class people with symptoms had them for longer than working class people.

Our enquiries into restrictions were concerned with the ability to do the following things without help in the period before death or before going into a hospital or hospice for the last time: get in and out of a bath or shower, dress and undress including shoes and fastenings, go to the toilet and cope on own when there, wash (and shave), feed self, cut own toenails, make a hot drink. People were also asked whether help had been needed at night. More of the working class people who died were reported to have needed help with feeding themselves for a year or more: $6 \%$ compared with $2 \%$ of middle class people. There were no other class differences.

\section{HOUSING ${ }^{2}$}

More middle class than working class people who died had had a telephone: $95 \%$ compared with $79 \%$, but similar proportions $(72 \%$ overall) had a washing machine. For almost a quarter $(23 \%)$ of both groups their homes were described as "an easy place for them" and no significant differences emerged when respondents were asked whether there were any problems with the position of the lavatory $(18 \%)$, the distance from the shops $(16 \%)$, or the stairs $(35 \%$ reported difficulties), although more middle class people had lived in bungalows: $17 \% v 10 \%$. However more of the working class than of the middle class were said to have had some other housing problem $-12 \% \quad v 5 \%$. Illustrations of the difficulties reported include:

"Not enough room after the bed had been brought downstairs. There was only one living room and with the bed in it it didn't leave much room for others (wife and son). We had to bring it downstairs because he couldn't walk upstairs and the toilet was downstairs anyway and there was no heating upstairs." (Son of man who died of lung cancer.)

"Her flat was on the top, third floor. It was too high up. She couldn't manage the stairs. She just never went out. The council could have helped by moving her into sheltered housing on the ground floor. That's what she really needed-to be in a flat where there was a warden to look after her. I tried to get her in but was told there was nowhere for her." (Sister of woman who lived alone and died of heart failure aged 74 years.)

Some of the problems could have been overcome by money and $15 \%$ of the working class compared with $7 \%$ of the middle class reckoned that cost was a problem in keeping the person's home warm enough.

\section{FINANCE}

Apart from any difficulties over heating their homes, $11 \%$ of the working class compared with $6 \%$ of the middle class were said to have had financial problems. There was no difference between the two groups in the proportions who had had a mobility allowance ( $8 \%$ had one), an attendance allowance $(15 \%)$, a disability pension $(6 \%)$, or financial help from relatives $(10 \%)$, but more of the working class had had supplementary benefit $(26 \% v 12 \%)$, a heating allowance $(13 \% v$ $4 \%)$, and a rent or rate rebate $(50 \% v 30 \%)$. But in spite of these additional sources of help respondents felt that twice as many of the working class than of the middle class people who died could have done with more financial help: $32 \%$ v $16 \%$. Clearly allowances are too low to overcome the financial problems faced by a substantial proportion of people in the months before their death: $40 \%$ of those receiving supplementary benefit, $34 \%$ of those with a rent or rate rebate, and $44 \%$ of those with a heating allowance were thought to have needed more financial help.

\section{COMMUNICATION $^{\mathrm{b}}$}

There were no differences between the middle and working class in the proportion thought to have known they were dying or to have known their diagnosis; neither were there any differences in respondents' assessments about whether knowing or not knowing had been best as it was, or whether they themselves had been able to find out all they wanted to know, or in their main sources of information and support. Similar proportions

${ }^{a}$ Questions about housing and finance were not asked about people who died suddenly and without any restrictions before people who died suddenly and without any restrictions before they were 65 years old or about those who had been in a hospit gr other institutions for a year
bee footnote on next page. 
of the two groups said they had talked to the person who died about his or her death $37 \%$ had done so if the person was thought to have realised they were dying).

\section{QUALITY OF LIFE AND TIME OF DEATH ${ }^{\mathrm{b}}$}

Towards the end of the interview two questions were asked about the timeliness of death and the quality of the person's life in the year before death. In assessing the timeliness of death respondents were asked to take the person's illness into account and then say whether they thought the person had died at the best time or whether it would have been better if he or she had died earlier or later. Most (59\%) people were thought to have died at the best time, for $22 \%$ it was thought better if they had died earlier, for $13 \%$ later, and for $6 \%$ there were other comments. There were no social class differences over this. Altogether $34 \%$ of the people who died were described as having had a good quality of life in the year before their death; this proportion was higher for middle class than for working class people: $43 \% v 30 \%$. The difference remained when deaths for which staff of residential homes were interviewed were excluded.

\section{Discussion}

Given that middle class people had lived, on average, rather longer than working class people it might have been expected that middle class people would have more symptoms, have been more restricted, and have had a generally poorer quality of life during the year before their death. None of these happened; on the contrary, middle class people were reported to have had a rather better quality of life during this time. A contributory cause to this difference seemed to be money. More working class people were felt to be in financial need; and among those who were thought to need more financial help only $26 \%$ were thought to have had a good quality of life, compared with $38 \%$ of those not in need. Other differences between middle class and working class people that may have played a part were housing and possibly rather poorer care. Private hospitals and private residential homes were less accessible to working class people and this may be why they needed a longer period of nursing care at home and also why more of them needed long term help with feeding before they died or went into hospital for the last time. Other indications that working class people may have received less good care were the higher level of criticism of the way they were looked after by domiciliary nurses, the apparent willingness of general practitioners to spend more time discussing things with middle class patients, and the fact that middle class patients were more likely to have general practitioners who trained in Great Britain. ${ }^{10} 16$

In many ways the experiences of middle class and working class people in the last year of their

${ }^{b}$ Questions about communications and the quality of life and timeliness of death were not asked for people who died suddenty and with no restrictions before they were 65 years old. lives were remarkably similar: for the most part they suffered from the same symptoms and had the same restrictions, and they spent similar lengths of time in hospitals where they were apparently cared for in similar ways. If their different ages are taken into account they were visited or neglected by their general practitioners to the same extent and they had similar communications problems, or lack of them.

The similarity of symptoms and restrictions, despite the fact that middle class people die at a later age, suggests that working class people may be aging earlier and be more subject to what Martin" has described as the "negative features of old age", which can be traced to poverty and powerlessness. Some of the things that money can buy may postpone the aging process and make the last year of life rather less unpleasant. The similarity of the findings in 1969 and 1987 supports results from other studies about the persistence of social inqualities, but indicates that in the year before death these are more related to social circumstances than to health.

A particular debt of gratitude goes to the relatives and associates of the people who died who contributed to the study. I am also grateful to the many people who helped; the interviewers, other colleagues-particularly Graham Farrow who checked this paper-and members of the Institute's Advisory committee. The study was funded by the Medical Research Council and done in collaboration with Clive Seale.

1 Department of Health and Social Security Research Working Group. Inequalities in health. London Department of Health and Social Security, 1980.

2 Davey Smith G, Bartley M, Blane D. The Black report on socioeconomic inequalities in health 10 years on. $B M \mathcal{J}$ 1990; 301: 373-7

3 Blane D, Davey Smith G, Bartley M. Social class differences in years of potential life lost: size, trends, and principal causes. BMF 1990; 301: 429-32.

4 Fox A J Goldblatt P O, Jones D R. Social class mortality differentials: artefact, selection or life circumstances? Epidemiol Community Health 1985; 39: 1-8.

5 Morris J N. Inequalities in health: ten years and a little further on. Lancet 1990; 336: 491-3.

6 Cartwright A, Hockey L, Anderson J L. Life before death. London: Routledge and Kegan Paul, 1973.

7 Cartwright A, Seale C. The natural history of a survey: an account of the methological issues encountered in a study of life account of the methological issues encountered in a stud
before death. London: The King's Fund, 1990.

8 Cartwright A. The role of hospitals in caring for people in the last year of their lives Age Ageing 1991; 20: 271-4.

9 Cartwright A. The role of residential and nursing homes in Cartwright A. The role of residential and nursing homes in
the last year of people's lives. Br $f$ Soc Work (in press).

10 Cartwright $\mathrm{A}$. The role of the general practitioner in caring for people in the last year of their lives. London: The King's Fund, 1990

11 Seale C. Community nurses and the care of the dying. Soc Sci Med (in press)

12 Seale C. Caring for people who die: the experience of family and friends Ageing and Society 1991; 10: 413-28.

13 Office of Population Censuses and Surveys Classification of occupations. London: HMSO, 1980.

14 Buchan I C, Richardson I M. Time study of consultations in general practice. Scottish Health Studies No 27 . Edinburgh: Scottish Home and Health Department, 1973.

15 Cartwright A, O'Brien M. Social class variations in health care and in the nature of general practitioner consultations. In - Stacey M, ed. The Sociology of the $N H S$ consultations. In . Stacey M, ed. The Sociology of the NHS. Sociological

6 Review Monograph No 22, University of Keele, 1976. London: Tavistock, 1981.

17 Cartwright A Medicine taking by people aged 65 or more $B r$ Med Bull 1990; 46: 63-76

18 Cartwright A, Smith C. Elderly people, their medicines and their doctors. London: Routledge, 1988.

19 Martin B. The cultural construction of ageing: or How long can the summer wine actually last? In: Bury $M$, Macinol J, eds Aspects of ageing. London: Department of Social Policy, Royal Holloway and Bedford New College (Social Policy Papers No 3) 1990. 